\title{
Evaluation the Use of the lux Reporter System pUC19-luxAB for Rapid and Sensitive Detection of Assimilable Organic Carbon (AOC) in Reverse Osmosis (RO) Feed Water
}

\section{Thi Tu Uyen Bui*}

Faculty of Biology and Biotechnology, University of Science, Hochiminh City, Vietnam

*Corresponding Author: Thi Tu Uyen Bui, Faculty of Biology and Biotechnology, University of Science, Hochiminh City, Vietnam.
Received: February 26, 2020

Published: March 16, 2020

(C) All rights are reserved by Thi Tu Uyen Bui.

\begin{abstract}
Assimilable organic carbon (AOC) in reverse osmosis (RO) feed water has been assumed to be the key determinant for microorganism growth leading to membrane fouling and limiting the use of this membrane technology. The lux reporter system developed in this study can be used as a membrane fouling indicator to estimate fouling potential of RO pre-treated feed water. The construction of bioluminescent reporter plasmids was done by integrating luxAB genes from Vibrio fischeri MJ1 downstream of a strong promoter (lacIQ) into high copy number plasmids pUC19. To investigate the use of the lux reporter for detection of AOC, the pUC19-luxAB system was introduced into a common marine bacterium, Vibrio cholerae A1552 by electroporation. The results showed that luxAB genes were successfully expressed in $V$. cholerae A1552 with the bioluminescence reading of $3.3 \times 10^{4}$ relative light unit (RLU), which was 3000 -fold greater than the background signal. The linear curve constructed by A1552 (pUC19-luxAB) with a coefficient $\left(\mathrm{R}^{2}\right)$ of 0.9761 showed that there was a strong correlation between bioluminescent intensity and glucose concentrations in a range of 0 - 100

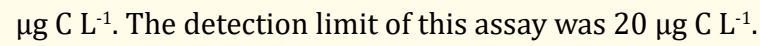

Keywords: Assimilable Organic Carbon (AOC); Lux Reporter System; RO; Fouling Indicator; Bioluminescence Measurement; pUC19-luxAB

\section{Introduction}

Reverse osmosis (RO) technologies are advanced solutions for wastewater treatment and water reuse that address the increase in clean water demand. In desalination systems, seawater is fed through a pre-treatment process, including screening, coagulation, sedimentation and microfiltration, to remove organic and colloidal substances before passing through the RO membranes where salts and impurities are removed under very high pressure (30 - 150 atm) [3]. However, membrane fouling that results in increases in operational and maintenance costs is a major obstacle to the widespread application of this technology. Biofouling caused by the growth of bacteria on the membrane surface is considered to be the most common form of membrane fouling [6]. One biofouling control strategy is the assessment of the fouling potential of feedwater according to fouling indicators. The concentration of AOC is directly correlated with the growth of heterotrophic bacteria in water systems. AOC has been widely used as a biofouling indicator for the prediction of biofouling in RO systems $[5,9,16]$.

Bacterial luciferases are the most extensively used among the luciferase family members as reporter genes for biological and biotechnology applications. Most bioluminescent species are marine bacteria of the genera Vibrio, Aliivibrio and Photobacterium. All luciferase systems detected in bacteria are basically encoded by the luxCDABE operon, in which luxAB genes encode the subunits of luciferase, while $\operatorname{lux} C D$ and $\operatorname{lux} E$ genes encode the fatty acid reductase complex, which are responsible for the synthesis of the luciferase aldehyde substrate. In the presence of flavin mononucleotide (FMN) and oxygen, luciferase oxidises a long-chain fatty aldehyde and releases energy in the form of visible light with an absorption 
Evaluation the Use of the Iux Reporter System pUC19-IuxAB for Rapid and Sensitive Detection of Assimilable Organic Carbon (AOC) in Reverse Osmosis (RO) Feed Water

maximum at $490 \mathrm{~nm}$ [7]. The lux systems of $P$. phosphoreum, $P$. leiognathi, $V$. harveyi, $V$. fischeri and $P$. lumininescens are the best reporter systems, which have been widely studied $[2,8,11,13,18]$. In a previous study conducted by Chua., et al. [2], the split reporter system containing only lux $A B$ is more effective and sensitive reporters, which produced 2.8-fold greater bioluminescent signal than the full luxCDABE system.

One of the main drawbacks to the use of bioluminescence reporter system is the achievement of reporter protein expression levels high enough to produce a signal that can be detected externally. Therefore, promoter lacIQ, a mutated promoter of the lacI gene (a single $\mathrm{C}->\mathrm{T}$ change in the -35 region) which causes a 10fold increase in lacI expression compared to the wild type promoter was used. The pUC19 plasmids that have a high copy number of between 500 and 700 copies per cells were also used to optimise the expression levels of the bacterial luminous genes $\operatorname{lux} A B$ [4]. In this study, the lux reporter system pUC19-lux $A B$ for the detection of AOC was investigated by introducing this system into the common marine bacterium $V$. cholerae, which has been known as a model of horizontal gene transfer is a transformable bacterium able to uptake DNA from the environment [14].

\section{Materials and Methods}

Bacterial strains, plasmids and media

The strains and plasmids used in this study are described in Table 1. V. fischeri MJ-1 and V. cholerae A1552 were grown in LuriaBertani 20 (LB20; $10 \mathrm{~g} \mathrm{~L}^{-1}$ tryptone, $5 \mathrm{~g} \mathrm{~L}^{-1}$ yeast extract and $20 \mathrm{~g}$ $\left.\mathrm{L}^{-1} \mathrm{NaCl} ; \mathrm{BD}\right)$ at $30^{\circ} \mathrm{C}$, and $E$. coli cells were cultured in LB (10 g $\mathrm{L}^{-1}$ tryptone, $5 \mathrm{~g} \mathrm{~L}^{-1}$ yeast extract and $10 \mathrm{~g} \mathrm{~L}^{-1} \mathrm{NaCl}$; BD) at $37^{\circ} \mathrm{C}$. EconoTaq PLUS GREEN 2X Master Mixes (Lucigen) were used in $\mathrm{PCR}$ reactions in this research.

\begin{tabular}{|l|c|c|}
\hline $\begin{array}{l}\text { Strains and } \\
\text { Plasmids }\end{array}$ & Relevant Characteristics & $\begin{array}{c}\text { Source of } \\
\text { Reference }\end{array}$ \\
\hline Strains & LuxAB genes & {$[8]$} \\
\hline V. fischeri MJ-1 & Marine strain & {$[12]$} \\
\hline V. cholerae A1552 & Chemical competent & Bio Lab \\
\hline E. coli C2987 & 2686 bp, Amp ${ }^{\mathrm{R}}$ & Add gene \\
\hline Plasmids & $\begin{array}{r}\text { Derived from pBSL181, 8300 } \\
\text { bp Cam }\end{array}$ & {$[17]$} \\
\hline pUC19 & & \\
\hline pKV34 & & \\
\hline
\end{tabular}

Table 1: Plasmids and bacterial strains used in the generation of bioluminescent reporter plasmids.

Amp: Ampicillin; Cam: Chloramphenicol.
Construction of bioluminescent reporter plasmids

Primers F-LuxAB -5'-TTCAGGGTGGTGAATATGAAGTTTGGAAATATTTGTTTTTC-3' and R-LuxAB -5'-GATCCTCTAGAGTCGACCTGCAGGCATGTTATGGTAAATTCATTTCGA TTTTT-3' were used to obtain the sequence of the 2084 bp $\operatorname{lux} A B$ genes from $V$. fischeri MJ-1 (AF170104.1) by PCR. In order to achieve high levels of light production, a $66 \mathrm{bp}$ highly expressed promoter, lacIQ, was cloned from pKV34 by PCR using primers F-LacIQ -5'-CTATGACCATGATTACGCCAAGCT TGCATGTGGTGCAAAACCTTTCGC-3' and R-LacIQ - 5'-ATTTCCAAACTTCATATTCACCAC CCTGAATTGACT-3'. pUC19 (NEB 5520, BioLabs, USA) was used as a backbone for the recombinant plasmid and was digested with SphI (NEB R3182, BioLabs) to linearise the plasmid. DNA fragments including the lacIQ promoter and the luxAB genes were cloned into the linear pUC19 using the NEBBuilder ${ }^{\circledR} \mathrm{HiFi}$ DNA Assembly Cloning Kit (NEB 5520, BioLabs). The constructed plasmid containing an $\mathrm{Amp}^{\mathrm{R}}$ marker was introduced into 5-alpha chemically competent E. coli (NEB C2987, BioLabs) by chemical transformation. The reporter plasmids were extracted from E. coli $\mathrm{C} 2987$ and the confirmation of the plasmid sequence was performed by PCR using primers F-LacIQ and R-Lux$A B$. The DNA fragment was transported to the Australian Genome Research Facility (AGRF; Westmead, NSW, Australia) for sequencing to confirm that the construction was successful.

\section{Electroporation}

Electrocompetent cells in this research were prepared based on the method of Liu [10]. Specifically, $V$. cholerae cells were cultured to an optical density at $\mathrm{OD}_{600 \mathrm{~nm}}=0.8$. The cells were harvested by centrifugation at $3360 \times g$ for $6 \mathrm{~min}$ at $4{ }^{\circ} \mathrm{C}$ and washed twice with ice cold $0.5 \mathrm{M}$ sucrose (BD). The washed cells were resuspended in the same solution and stored at $-80{ }^{\circ} \mathrm{C}$ until used. For electroporation, $50 \mu$ aliquots of competent cells were mixed with 1 - 5 $\mu \mathrm{l}$ plasmids and transferred to ice cold $0.1 \mathrm{~cm}$-gap electroporation cuvettes (Bio-Rad, Richmond, California) and inserted into the electroporation chamber of a Micropulser (Bio-Rad, Richmond, California) which was set at $1.8 \mathrm{kV}$. After the discharge, the cell suspensions were immediately mixed with $1 \mathrm{ml} \mathrm{LB} 20$ and incubated at 30 ${ }^{\circ} \mathrm{C}$, respectively for $1 \mathrm{~h}$ with shaking at $250 \mathrm{rpm}$. These suspensions were diluted and plated on LB20 containing $100 \mu \mathrm{g} \mathrm{ml}^{-1}$ for carbenicillin and incubated at $30^{\circ} \mathrm{C}$ for 24 to $48 \mathrm{~h}$.

\section{Bioluminescent measurement}

The reporter strain was grown in LB20 supplemented with 100 $\mu \mathrm{g} \mathrm{ml}^{-1}$ for carbenicillin and incubated at $30{ }^{\circ} \mathrm{C}$ overnight with shaking at $200 \mathrm{rpm}$. The bacterial cultures were diluted to $\mathrm{OD}_{600 \mathrm{~nm}}$ of 0.4 . Bacterial cells were harvested by centrifugation $7462 \times g$ for 5 min at room temperature and washed twice with artificial seawa- 
ter (ASW) (13.5 g L ${ }^{-1} \mathrm{NaCl}, 2.5 \mathrm{~g} \mathrm{~L}^{-1} \mathrm{MgCl}_{2} .6 \mathrm{H}_{2} \mathrm{O}, 1.96 \mathrm{~g} \mathrm{~L}^{-1} \mathrm{Na}_{2} \mathrm{SO}_{4^{\prime}}$ $0.107 \mathrm{~g} \mathrm{~L}^{-1} \mathrm{NaHCO}_{3}, 0.55 \mathrm{~g} \mathrm{~L}^{-1} \mathrm{CaCl}_{2} .2 \mathrm{H}_{2} \mathrm{O}, 0.5 \mathrm{~g} \mathrm{~L}^{-1} \mathrm{NH}_{4} \mathrm{Cl}, 0.33 \mathrm{~g} \mathrm{~L}^{-1}$ $\mathrm{KCl}, 0.23 \mathrm{~g} \mathrm{~L}^{-1} \mathrm{~K}_{2} \mathrm{HPO}_{4^{\prime}} 0.053 \mathrm{~g} \mathrm{~L}^{-1} \mathrm{KBr}, 0.0107 \mathrm{~g} \mathrm{~L}^{-1} \mathrm{SrCl}_{2} .6 \mathrm{H}_{2} \mathrm{O}$ and $0.0107 \mathrm{~g} \mathrm{~L}^{-1} \mathrm{H}_{3} \mathrm{BO}_{3}$ and adjusted to $\mathrm{pH}$ 7.5) [8]. The washed cells were resuspended in ASW containing $100 \mathrm{\mu g} \mathrm{ml}^{-1}$ for carbenicillin and incubated at room temperature for $30 \mathrm{~min}$.

Bacterial cultures were transferred to a 24-well multiwell, tissue culture treated plate (BD Falcon ${ }^{\mathrm{TM}}$ ) containing carbon solutions at different concentrations. Bioluminescence was measured immediately after adding the substrate for $10 \mathrm{~s}$ using an integration time of $1 \mathrm{~s}$ with the Infinite 200 PRO plate reader (Tecan, Austria) using Magellan software (Tecan, Austria). For bioluminescent kinetic assays, bioluminescent output was measured automatically every $2.5 \mathrm{~min}$ for $15-20 \mathrm{~min}$. The procedure is demonstrated in Figure 1. The results were expressed as RLU. Each experiment was conducted in triplicate.

A 1\% stock of aldehyde substrate, decanal (Sigma-Aldrich), was prepared in ethanol (Sigma-Aldrich). The stock solution was diluted with phosphate buffered saline (PBS, Melford, UK) to a final concentration of 6.4 Mm. Carbon solutions, glucose (BD) and LB were prepared in ASW as sole carbon sources at a range of concentrations $\left(0,20,40,60,80\right.$ and $\left.100 \mu \mathrm{g} \mathrm{C} \mathrm{L}^{-1}\right)$ and concentrations $(0$, $0.7,1.4,2.8,5.6$ and $11.3 \mathrm{mg} \mathrm{C} \mathrm{L}^{-1}$ ), respectively. These solutions were sterilised by filtering through $0.22 \mu \mathrm{m}$ pore size membranes.
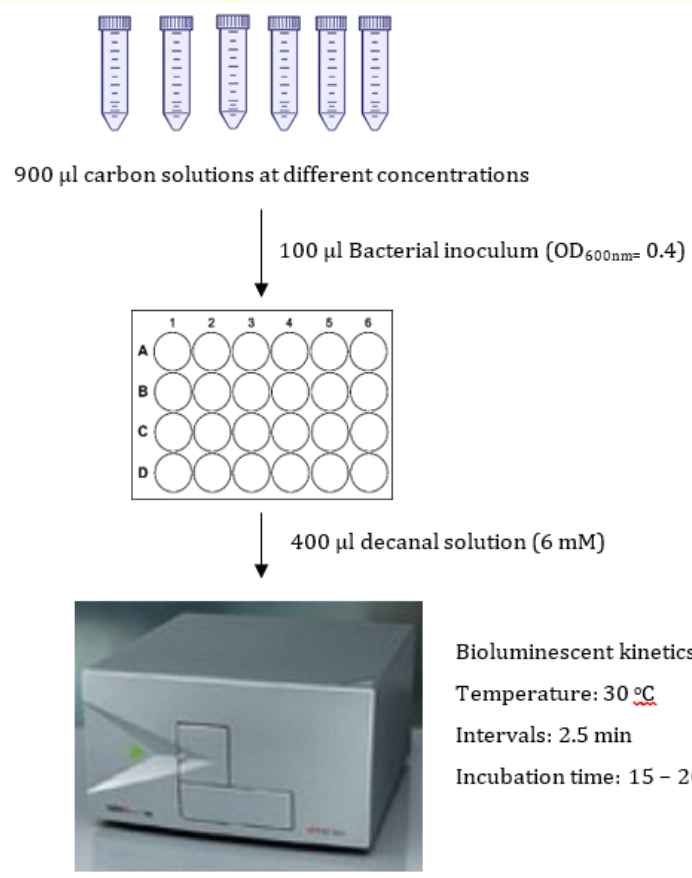

Bioluminescent kinetics assays

Temperature: $30^{\circ} \mathrm{C}$

Intervals: $2.5 \mathrm{~min}$

Incubation time: $15-20 \mathrm{~min}$

Figure 1: Schematic of bioluminescent experiment. Bioluminescence was measured automatically following the kinetics assays using Magellan software.

\section{Results}

DNA fragments encoding the $\operatorname{luxAB}$ genes and lacIQ promoter were amplified by PCR using primers designed from Genome Compiler software. The PCR products were electrophoresed on $1.0 \%$ agarose gel (Figure 2).

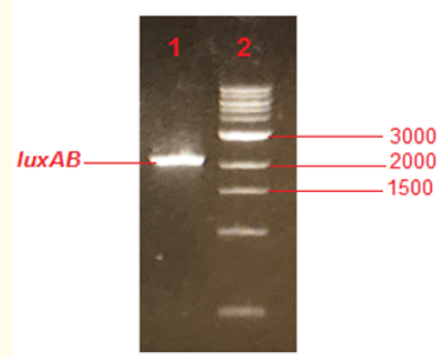

(A)

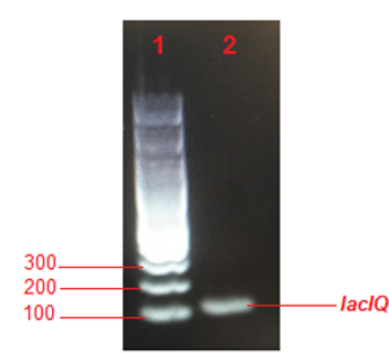

(B)
Figure 2: PCR amplification of (A) luxAB using primers F-LuxAB and R-LuxAB. Lane 1 is the PCR product (2127 bp); lane 2 is $1 \mathrm{~Kb}$ DNA ladder and (B) lacIQ using F-LacIQ and R-LacIQ. Lane 1 is 100 bp DNA ladder; lane 2 is the PCR product (111 bp).

These DNA fragments were cloned into a linear pUC19 vector by Gibson Assembly (NEB, Ipswich, MA USA). The pUC19-luxAB reporter plasmids were introduced into E. coli C2987. These recombinant vectors were confirmed by restriction digestion using EcoRI (Figure 3). The confirmation of the DNA fragments was carried out by PCR (Figure 4) and sequencing using primers F-lacIQ and R-luxAB. The results indicated that $\operatorname{lu} A B$ genes downstream of promoter lacIQ were successfully cloned into pUC19. pUC19lux $A B$ reporter plasmids were transformed into V. cholerae A1552 by electroporation.

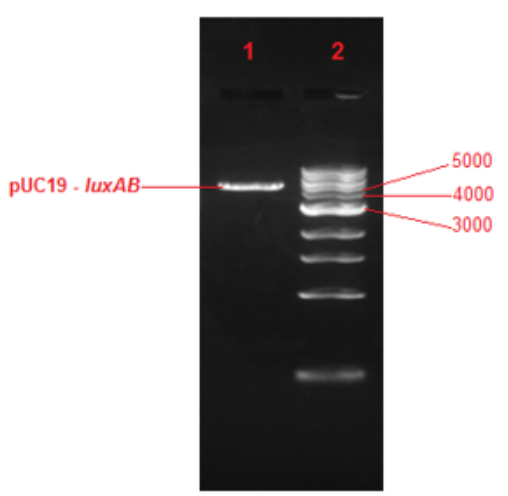

Figure 3: Restriction digestion of pUC19-luxAB with EcoRI. Lane 1 is the product of digestion with EcoRI (4836 bp); lane 2 is $1 \mathrm{~Kb}$ DNA ladder. 


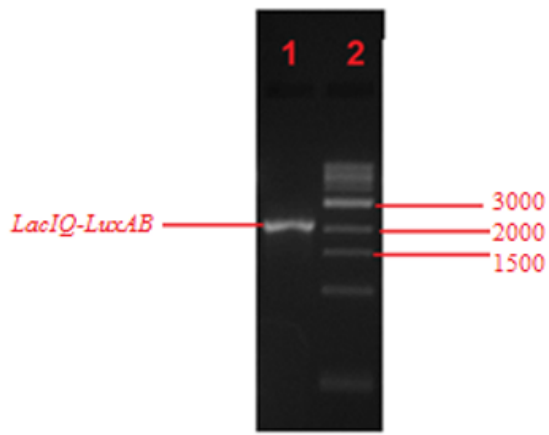

Figure 4: PCR amplification of lacIQ-luxAB using F-lacIQ and RluxAB primers. Lane 1 is the PCR product (2238 bp); lane 2 is $1 \mathrm{~Kb}$ DNA ladder.

The light production of $V$. cholerae A1552 (pUC19-luxAB) was $3.3 \times 10^{4} \mathrm{RLU}$ compared to $1.1 \times 10^{6} \mathrm{RLU}$ of $V$. fischeri MJ1. The findings are consistent with the results of previous studies that bioluminescent intensity of reporter strains expressing luxAB ranges from $3.6 \times 10^{3}$ to $3.9 \times 10^{5} \mathrm{RLU}[1 ; 19]$. This indicated that luciferase was successfully expressed in V. cholerae A1552.

The production of bioluminescence by $V$. cholerae A1552 (pUC19-lux $A B$ ) was investigated at different carbon concentrations ranging from 0 to $11.2 \mathrm{mg} \mathrm{C} \mathrm{L}^{-1}$ for $20 \mathrm{~min}$ (Figure 5). The results showed that at low carbon concentrations $\leq 1.4 \mathrm{mg} \mathrm{C} \mathrm{L}^{-1}$, V. cholerae A1552 (pUC19-luxAB) reached the maximum signal production after $5 \mathrm{~min}$ incubation and $7.5 \mathrm{~min}$ incubation at high carbon concentrations from $2.8-11.2 \mathrm{mg} \mathrm{C} \mathrm{L}^{-1}$. These results demonstrated that at low nutrient concentrations, the bacterium required shorter incubation times to utilise all available carbon in the solution. The bioluminescence of the reporter strain decreased suddenly after reaching the peak. This rapid reduction was attributed to nutrient limitation. In an appropriate concentration range, bioluminescence intensity increased with increases in carbon concentration. At a low concentration of $0.7 \mathrm{mg} \mathrm{C} \mathrm{L}^{-1}$, the maximum bioluminescence was $3.1 \times 10^{3} \mathrm{RLU}$, while at a high concentration of $2.8 \mathrm{mg} \mathrm{C} \mathrm{L}^{-1}$, the bioluminescent response was $4.5 \times 10^{3} \mathrm{RLU}$ (Figure 5).

The bioluminescence of $V$. cholerae A1552 (pUC19-luxAB) in the presence of glucose were measured at concentrations ranging

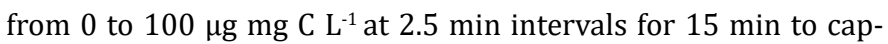

ture the maximum levels of bioluminescence (Figure 6). Glucose was used as it gave the greatest sensitivity for the detection of low amounts of carbon, expressed as glucose equivalent in $\mu \mathrm{g} \mathrm{C} \mathrm{L}^{-1}$ [15]. These results showed that the bioluminescence increased with the increase of glucose concentration. The maximum bioluminescence

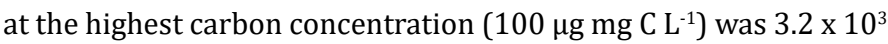
RLU, while at the lowest concentration was $2.6 \times 10^{3} \mathrm{RLU}$. It is noted that bioluminescence intensity of V. cholerae A1552 (pUC19-luxAB) increased exponentially and reached the maximum after 5 min incubation at all tested glucose concentrations. The shorter incubation time to reach the maximum bioluminescence enables this to be a rapid AOC assay. After reaching the peak, the bioluminescence of the tested strain sharply decreased over $70 \%$ by the end of the experiment. The sudden reduction of bioluminescence indicates that all available glucose has been used by the tested strain.

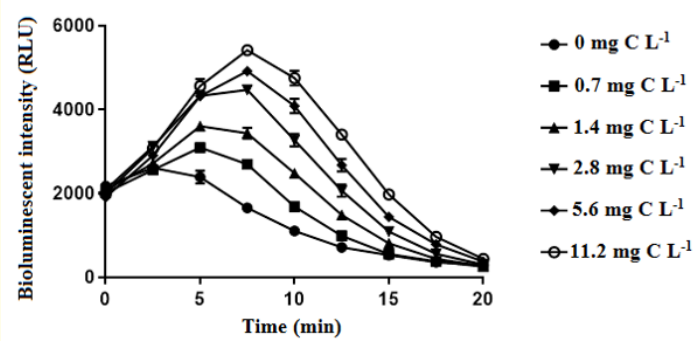

Figure 5: Bioluminescent intensity of V. cholerae A1552 (pUC19lux $A B$ ) in response to different LB dilutions over $20 \mathrm{~min}$. The bioluminescent signals are for bacterial cultures $\left(\mathrm{OD}_{600 \mathrm{~nm}}=0.4\right)$ after addition of the substrate. The error bars represent standard deviations of the means.

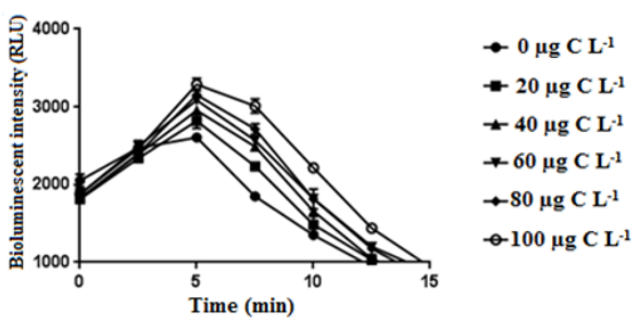

Figure 6: Bioluminescent intensity of V. cholerae A1552 (pUC19$\operatorname{lux} A B)$ in response to different glucose concentrations. The bioluminescent signals are for bacterial cultures at an $\mathrm{OD}_{600 \mathrm{~nm}}=0.4$. The error bars indicate standard deviation of the means. 
The maximum values of bioluminescence achieved after 5 min incubation of V.cholerae A1552 (pUC19-luxAB) plotted against glucose concentrations is demonstrated in figure 7. Results showed that the curve of $V$. cholerae A1552 (pUC19-luxAB) bioluminescence plotted against $C$ concentration had $R^{2}$ of 0.9761 . In terms of variation, the findings from this study are consistent with the results obtained from previous studies of Ma., et al. [11] and Jeong., et al. [8] that showed a strong and linear correlation between bioluminescence and glucose concentrations with $\mathrm{R}^{2}>0.97$. Therefore, it is possible to estimate the AOC concentration expressed in $\mu \mathrm{g}$ glucose-C $\mathrm{L}^{-1}$ in seawater samples by using the lux reporter system. In addition, the pUC19-luxAB system was highly sensitive with a detection limit of $20 \mu \mathrm{g} \mathrm{C} \mathrm{L}{ }^{-1}$ (an increase of $2.2 \times 10^{2} \mathrm{RLU}$ over background bioluminescent intensity), demonstrating its usefulness for the AOC detection at low concentrations that range from

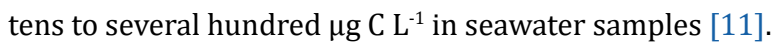

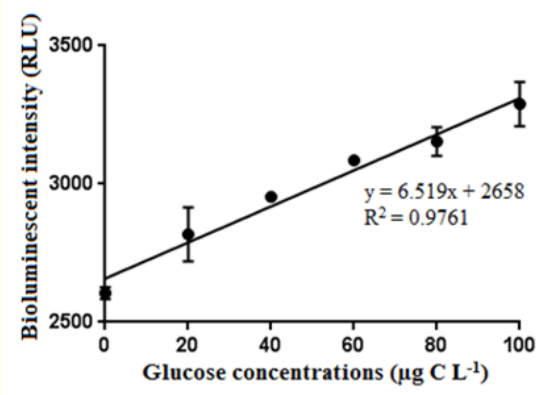

Figure 7: The linear relationship between the concentrations of glucose and the maximum bioluminescence in $V$. cholerae A1552 (pUC19-luxAB). The error bars indicate standard deviation of the means.

\section{Discussion}

AOC compounds, which are quickly metabolised by microorganisms are considered to be important sources of carbon and energy for bacteria. There is a significant correlation between AOC concentration and the growth of heterotrophic bacteria, which results in biofouling on RO membranes. Typically, the growth of microorganisms is limited when the AOC concentration is lower than $20 \mu \mathrm{g} \mathrm{C} \mathrm{L}{ }^{-1}$, while at AOC concentrations greater than $50 \mu \mathrm{g}$ $\mathrm{C} \mathrm{L}^{-1}$, there is a significant growth [11]. The AOC concentration is an important factor used to control the growth of microorganisms and microbial activity in aquatic environments. Therefore, understanding of the impact of desalination pretreatment processes on the removal of AOC is necessary to prevent or minimise membrane fouling. In general, the plate count assay for AOC measurement requires several days to complete. Conversely, bioluminescencebased AOC assays take only minutes to perform [9]. An added advantage of the bioluminescence-based AOC assay is the extreme sensitivity of detection, which permits the estimation of AOC at very low concentrations [7].

In the current study, we developed the lux system by integrating IuxAB genes downstream of the strong promoter lacIQ into a high copy number pUC19 to maximise the expression levels. A previous study reported that the IuxAB genes from $V$. harveyi were transferred to different bacteria using a wide range of plasmids, but the luciferase activity of these modified strains was reduced up to $98 \%$ in comparison to the wild type [15]. In this research, the modified strains V. cholerae A1552 (pUC19-luxAB) produced the bioluminescent intensity approximately 30 -fold lower than that of the wild type, but the bioluminescent intensity of these transformed strains was over 3000-fold greater than the background bioluminescent intensity. Thus, the constructed lux reporter system may be suitable as reporter plasmids for the measurement of AOC.

The maximum values of bioluminescence were used in the establishment of the linear relationship to carbon concentrations to ensure that all carbons are metabolised when bioluminescence reaches maximum intensity. The peak bioluminescence directly correlates to carbon concentration. In this study, the linear correlation between bioluminescence and glucose concentration was determined for the modified strain $V$. cholerae A1552 (pUC19-luxAB). The comparison of the $\mathrm{R}^{2}$ values (greater than 0.97 ) indicates the curve can be used as standard curves for quantification of AOC. The modified strain responds to very low glucose concentrations $(20 \mu \mathrm{g}$ $\mathrm{C} \mathrm{L}^{-1}$ ). Therefore, these curves can be used for predicting AOC concentrations expressed in $\mu$ g glucose-C $\mathrm{L}^{-1}$. At low carbon concentrations ( $\leq 1.4 \mathrm{mg} \mathrm{C} \mathrm{L}^{-1}$ ), it took a shorter time to reach the maximum level of bioluminescence compared to higher carbon concentrations ( $\geq 2.8 \mathrm{mg} \mathrm{C} \mathrm{L}^{-1}$ ) (Figure 5). It is recommended that for AOC measurements based on a linear curve, reporter strains should take a similar amount of time to reach the maximum bioluminescence at all tested carbon concentrations. For a very high carbon concentration, to ensure a linear relationship between biolumines- 
Evaluation the Use of the lux Reporter System pUC19-IuxAB for Rapid and Sensitive Detection of Assimilable Organic Carbon (AOC) in Reverse Osmosis (RO) Feed Water

cence and substrate concentration, a sample needs to be diluted due to the saturation of bioluminescence. The downward trend after reaching maximal light output may be attributed to a decrease in metabolic activity and therefore the availability of FMN, which is oxidised to make energy required for the light reaction [7]. Furthermore, the increase in density of the initial inoculum shortened the bioluminescence-based AOC assay time to $10 \mathrm{~min}$. The current research describes a rapid assay for AOC measurement which takes only minutes to perform. To minimise disadvantages caused by membrane fouling in RO systems, rapid monitoring assays are highly recommended to ensure prompt action is taken to control the AOC in feed water in time.

\section{Conclusions}

The bioluminescent reporter system composed of a pUC19 backbone containing luxAB genes and a strongly expressed promoter (lacIQ) was successfully introduced into V. cholerae A1552, creating A1552 (pUC19-luxAB). The reporter strain generated bioluminescent value of $3.3 \times 10^{4} \mathrm{RLU}$, which was 3000 -fold greater than the background signal. The linear curve constructed by A1552 (pUC19-luxAB) with $\mathrm{R}^{2}$ of 0.9761 showed that there was a strong correlation between bioluminescent intensity and glucose concentrations in a range of $0-100 \mu \mathrm{g} \mathrm{C} \mathrm{L}^{-1}$. The detection limit of this assay was $20 \mu \mathrm{g} \mathrm{C}^{-1}$ In the current study, the time needed to perform the bioluminescence-based AOC assay was 10 min rather than 30 - 60 min described in other studies $[8,18]$.

Bioluminescent AOC tests developed in this study can be used as membrane fouling indicators to estimate fouling potential of RO pre-treated feed water. This early warning system can save on costs associated with RO membrane fouling, including additional energy costs, chemical cleaning and membrane installation. In comparison to previously developed AOC assays, the AOC assays performed in this study were faster and would allow for prediction of membrane fouling potential and prompt and effective remedial action. In addition, this simple bioluminescent detection can be used to assess the efficiency of pre-treatment processes allowing for development of more effective pre-treatment processes to improve RO feed water quality.

Further work would be introducing the lux reporter system pUC19-luxAB into marine potential strains with a broad metabolic potential relative to AOC components in seawater for the aim of construction of standard curves showing the linear relationship between bioluminescence and AOC components. This method is expected to give better estimation of the AOC concentration rather than an AOC-equivalent concentration.

\section{Acknowledgements}

I am especially thankful to Prof. Diane McDougald and Dr. Shuyang Sun for their knowledge, suggestions and support throughout my research. I would like to express my appreciation to the ithree Institute at Technology Sydney University for providing lab facilities to.

\section{Bibliography}

1. Andreu N., et al. "Optimisation of bioluminescent reporters for use with mycobacteria”. PloS One 5.5 (2010): e10777.

2. Chua C., et al. "Improved sensitivity of the in vivo lux reporter system in measuring reactive oxygen species during antibiotic treatment of Escherichia coli". Journal of Experimental Microbiology and Immunology 18 (2014): 114-120.

3. Giwa A and Ogunribido A. "The applications of membrane operations in the textile industry: a review". Current Journal of Applied Science and Technology 2.3 (2012): 296.

4. Glascock CB and Weickert MJ. "Using chromosomal lacIQ1 to control expression of genes on high-copy-number plasmids in Escherichia coli". Gene 223 (1998): 221-231.

5. Haddix PL., et al. "Characterization of bioluminescent derivatives of assimilable organic carbon test bacteria”. Apply and Environmental Microbiology 70.2 (2004): 850-854.

6. Iorhemen OT., et al. "Membrane bioreactor (MBR) technology for wastewater treatment and reclamation: membrane fouling". Membranes 6.2 (2016): 33.

7. Jablonski E and DeLuca M. "Properties and uses of immobilized light-emitting enzyme systems from Beneckea harveyi". Clinical Chemistry 25.9 (1979): 1622-1627.

8. Jeong S., et al. "A rapid bioluminescence-based test of assimilable organic carbon for seawater". Desalination 317 (2013): 160-165.

9. LeChevallier MW., et al. "Development of a rapid assimilable organic carbon method for water". Apply and Environmental Microbiology 59.5 (1993): 1526-1531.

10. Liu IRIS., et al. "The effect of spheroplast formation on the transformation efficiency in Escherichia coli DH5 $\alpha$ ". Journal of Experimental Microbiology and Immunology 9 (2006): 81-85. 
11. Ma J., et al. "Assimilable organic carbon (AOC) in soil water extracts using Vibrio harveyi BB721 and its implication for microbial biomass". PloS One 7.5 (2012): e28519.

12. Matz C., et al. "Biofilm formation and phenotypic variation enhance predation-driven persistence of Vibrio cholerae". Proceedings of the National Academy of Sciences of the United States of America 102.46 (2005): 16819-16824.

13. Mun E., et al. "Measurements of assimilable organic carbon (AOC) in high saline conditions using P17". Water Science and Technology Water Supply 13.2 (2013): 265-272.

14. Seitz P and Blokesch M. "DNA-uptake machinery of naturally competent Vibrio cholerae". Proceedings of the National Academy of Sciences of the United States of America 110.44 (2013): 17987-17992.

15. Tehrani GA., et al. "Molecular cloning and expression of the luciferase coding genes of Vibrio fischeri". African Journal of Biotechnology 10.20 (2011): 4018-4023.

16. Van Der Kooij D., et al. "Determining the concentration of easily assimilable organic carbon in drinking water". American Water Works Association 74.10 (1982): 540-545.

17. Viswanathan K., et al. "Mutational analysis of the Myxococcus xanthus $\Omega 4406$ promoter region reveals an upstream negative regulatory element that mediates C-signal dependence". Journal of Bacteriology 188.2 (2006): 515-524.

18. Weinrich LA., et al. "Bioluminescence-based method for measuring assimilable organic carbon in pretreatment water for reverse osmosis membrane desalination". Apply and Environmental Microbiology 77.3 (2011): 1148-1150.

19. Wiles S., et al. "Alternative luciferase for monitoring bacterial cells under adverse conditions". Apply and Environmental Microbiology 71.7 (2005): 3427-3432.

\section{Assets from publication with us}

- Prompt Acknowledgement after receiving the article

- Thorough Double blinded peer review

- Rapid Publication

- Issue of Publication Certificate

- High visibility of your Published work

Website: https://www.actascientific.com/

Submit Article: https://www.actascientific.com/submission.php

Email us: editor@actascientific.com

Contact us: +919182824667

Citation: Thi Tu Uyen Bui. "Evaluation the Use of the lux Reporter System pUC19-luxAB for Rapid and Sensitive Detection of Assimilable Organic Carbon (AOC) in Reverse Osmosis (RO) Feed Water". Acta Scientific Microbiology 3.4 (2020): 145-151. 